\section{Territorio, lugares y salud: redimensionar lo espacial en salud pública}

\author{
Territory, places, and health: resizing spatiality in \\ public health
}

Território, espaços e saúde: redimensionar o espaço em saúde pública
Astrid Natalia Molina Jaramillo 1

doi: 10.1590/0102-311X00075117

\section{Resumen}

El propósito de este escrito es avanzar en la lectura del proceso de salud-enfermedad en clave territorial. La teorización sobre el vínculo salud y ambiente debe extenderse desde las tipologías médicas, y su énfasis en la distribución del riesgos ambientales (físico, biológico, químico), hacia el reconocimiento de la producción social y subjetiva de los territorios. Para avanzar en esta teorización la salud pública debe enriquecerse con la integración de nociones propias de las ciencias sociales como la apropiación del espacio, territorio-territorialidades y lugares. Además, ha de orientarse desde una mirada escalar hacia los microterritorios, pues es en el escenario de los territorios locales y en los lugares cotidianos de la vida, donde se concretan los modos de vivir, de enfermar $y$ de construir salud.

Geografía; Proceso Salud-Enfermedad; Medio Ambiente y Salud Pública; Desigualdades en la Salud

\section{spondencia}

A. N. Molina Jaramillo

Universidad de Antioquia.

Calle 62 \# 52-59, oficina 309, Medellín, Colombia.

anatalia.molina@udea.edu.co

1 Universidad de Antioquia, Medellín, Colombia. 
"Es preciso considerar que cada sociedad es, ante todo, un modo propio de estar juntos lo que implica siempre que toda sociedad se instituye como tal en la construcción de su espacio. Por lo tanto, no es posible una separación entre lo social y lo espacial (...). El ser social es indisociable del estar. Es preciso recuperar esa dimensión material sobre todo en momentos, como el que vivimos, en que se da cada vez más importancia a la dimensión simbólica, casi siempre de modo unilateral, como si lo simbólico se opusiese a lo material” 1 (p. 229-30).

\section{Introducción}

La preocupación por explicar el vínculo entre salud y ambiente es fundamental en el desarrollo de las ciencias de la salud. Desde el antiguo pensamiento hipocrático, el estudio de los lugares sanos y los lugares enfermos fue el camino para prevenir y curar las enfermedades a partir del control de factores ambientales 2. Las ideas hipocráticas resurgen durante el proceso de modernización para dar lugar a las llamadas topografías médicas del paradigma higienista del siglo XVIII y al análisis de distribución de peligros bacteriológicos (paradigma del germen) en el siglo XIX 3; en ambas perspectivas el interés era la localización y control de circuitos biológico-espaciales de la enfermedad bajo las llamadas geografías médicas ${ }^{4}$. Hasta entonces, el análisis de los aspectos ambientales en salud pública privilegió una concepción del ambiente como espacio ecológico externo, y una teorización centrada sobre factores primarios de diseminación o historia natural de la enfermedad para explicar la situación de salud de las poblaciones. Se trata una naturaleza externa a las personas que determina sus procesos mórbidos 5 .

Avanzado el siglo XX, la conceptualización del ambiente natural, como factor explicativo de la enfermedad, encuentra un límite en la transición epidemiológica hacia enfermedades no infeccionas y crónicas, y debe recurrirse a los aportes de la geografía social para explicar los procesos mórbidos, a partir de categorías como la densidad poblacional, el nivel de vida e ingresos, las comunicaciones y las costumbres de las poblaciones. Esto posibilitó un abordaje multivariado de la noción de ambiente como sistema de relaciones y permitió el estudio de la enfermedad como complejo ecopatógeno 6 . Los estudios de distribución espacial de la enfermedad avanzan hacia la delimitación político-fiscal de las unidades territoriales locales, como unidades socioespaciales, y se hace explícito el interés por una descentralización de las respuestas en salud en microáreas, definidas homogéneamente y aparentemente desconectadas de los contextos sociopolíticos más amplios 4.

Sin embargo, la expansión del modelo capitalista durante la segunda mitad del siglo XX, y la creciente globalización de las políticas económicas del neoliberalismo desde 1980, hicieron ineludible la apertura a otras vías de comprensión de los procesos mediadores de la relación entre territorios específicos y resultados en salud 7,8. El crecimiento del capitalismo de mercado ha generado nuevas formas de distribución de la enfermedad y muerte, la salud y la desigualdad en el mundo y en el interior de los países, como consecuencia de los modos hegemónicos de ordenar el territorio desde los grandes poderes globales 9,10 .

Con el aumento persistente de las desigualdades territoriales en salud 11,12, la multiplicación de las formas de despojo y pérdida de los lugares de vida 13, y las consecuentes afectaciones sobre la salud de las personas 14,15,16,17, se impone la necesidad de revaluar la clásica concepción causal-lineal del ambiente sobre la morbi-mortalidad de la población. Una mirada sobre los procesos de configuración territorial posibilita descentrar el análisis de los factores biológicos, físicos y químicos del ambiente para dar cabida a una comprensión de los modos de hacer salud, enfermar y morir, como procesos sociales que se asientan en los lugares donde se construye la vida. Para esto, se precisa de un acercamiento a diferentes escalas geográficas que permita seguir las conexiones entre las determinaciones globales de desarrollo económico neoliberal y las posibilidades concretas de construir salud en los escenarios locales. Más que una jerarquización lineal desde lo global hacia lo local -top-down-, considerar las escalas espaciales implica atender a la simultaneidad de procesos y la multiplicidad de tramas históricas y socioculturales que muestran la coexistencia de lo global y lo local en los lugares de la vida cotidiana y las acciones de las personas sobre sus territorios 18. En este sentido, la territorialidad deviene una categoría relacional, que permite seguir la configuración de los procesos de salud, a través de distintos órdenes espaciales. Como lo plantea Samaja ${ }^{19}$, se trata de repensar el medio ambiente y 
las poblaciones más allá de la instrumentalidad de esa relación, para verla como una situación sociohistórica y proyecto de liberación por los actores sociales.

La concepción del territorio, como categoría relacional, implica una redefinición del concepto de territorio usado en las políticas públicas en salud, dando lugar a propuestas más amplias que la del territorio político-administrativo y confiriéndole una mayor densidad teórica 20. Para avanzar en la ruta de reflexión teórica de las relaciones entre territorio, lugares y salud, este escrito se desarrolla en tres momentos. En primer lugar, un acercamiento a cómo se ha conceptualizado la relación entre territorio y salud en la salud pública. En segundo lugar, una enunciación de los aportes teóricos de las ciencias sociales, en torno a las categorías mediadoras del vínculo salud-territorio. $\mathrm{Y}$ en tercer lugar, la apuesta por una territorialización de la salud; esto es, la comprensión del proceso de construcción de salud desde los "pequeños" territorios, como un proceso de apropiación del espacio para la vida y el bienestar común, desde una dialéctica entre las determinaciones globales y las acciones locales de trasformación.

\section{La comprensión de la relación territorio-salud en salud pública}

La pregunta por el vínculo ambiente-población-salud está en el centro del interés del movimiento sanitarista en Europa (finales del siglo XVIII) y da lugar a una salud pública inicialmente preocupada por mejorar las condiciones de vida de la población para evitar la exposición a miasmas -causas de la enfermedad- y por definir las responsabilidades estatales en el control del funcionamiento social 3 . Los movimientos de higiene pública, que se alimentan posteriormente con la aparición del criterio microbiológico para la explicación de la enfermedad, estaban concentrados en vigilar las epidemias urbanas y en administrar acciones para atacar focos de enfermedad, con lo que configuraron técnicas de control científico y político del ambiente 21. Algunos efectos de este discurso higienista están presentes todavía en sistemas de salud actuales, que siguen configurándose en el marco modelos de asistencia pública y control poblacional de la enfermedad, y bajo la concepción del territorio como ambiente físico contenedor de vectores de enfermedad o riesgos. La lucha contra miasmas, microbios y pobres permanece en prácticas las sanitarias; el control del cuerpo social es el objetivo de la higiene y su diagnóstico y localización geográfica el instrumento para ejecutar mecanismos de administración de la vida social y regular a las "sociedades de riesgo" 22.

Como herencia de esta construcción histórica, la teorización de los procesos territoriales en salud pública ha estado largamente vinculada a la definición del territorio como espacio físico externo, que se entiende como referencia a un espacio que enferma o que cura, a zonas insalubres o salubres. Bajo esta conceptualización, el territorio es una entidad independiente y separable de la sociedad e interesa su base natural, que es científica y objetivamente delimitable 23,24 . Esta mirada se corresponde con la perspectiva epidemiológica clásica del riesgo, cuestionada por Almeida Filho et al. 25, que propone un análisis de los determinantes en salud, en función de su probabilidad de ocurrencia en una poblaciónárea geográfica específica y en un periodo de tiempo.

Lo anterior se evidencia, por ejemplo, en la definición de salud ambiental de la Organización Mundial de la Salud (OMS) 26 que enuncia ambiente y territorio como nociones desconectadas: " $\mathrm{La}$ salud ambiental está relacionada con todos los factores físicos, químicos y biológicos externos de una persona. Es decir, que engloba factores ambientales que podrían incidir en la salud y se basa en la prevención de las enfermedades y en la creación de ambientes propicios para la salud. Por consiguiente, queda excluido de esta definición cualquier comportamiento no relacionado con el medio ambiente, así como cualquier comportamiento relacionado con el entorno social y económico y con la genética". El énfasis está en la concepción de entornos saludables o insalubres, de acuerdo con la presencia de factores de riesgo medioambiental, bajo la cual la función de la salud pública es la de proteger a los individuos del medio ambiente, de un hábitat en el que las personas están inmersas y no pueden modificar la intensidad de las afectaciones de la naturaleza 5. Los factores de riesgo físico serían así producto de condiciones externas de los territorios que se "ocupan”, y el rol del salubrista sería el control de estos factores y el aseguramiento de infraestructura sanitaria de las comunidades, que quedan relegadas a la recepción pasiva de influencias del medio y de las acciones sanitarias. 
En esta vía, el territorio es concebido como espacio contenedor de riesgos naturales y área políticamente delimitada bajo la administración del Estado; es una variable de delimitación geográfica-ambiental, que se presume independiente de procesos sociales de orden político y económico más amplio.

Por otro lado, la medicina social del siglo XVIII abrió también una vía de pensamiento alrededor de la relación entre pobreza económica y enfermedad en las clases bajas de la población 21. Desde entonces se inaugura la pregunta por la relación entre enfermedad y procesos sociales y económicos, que vuelve a hacerse vigente desde mitad del siglo XX con la transición epidemiológica hacia enfermedades no infeccionas y crónicas que aumentan los índices de morbimortalidad de la población y que permiten el avance de la geografía social de la medicina hacia análisis multifactoriales bajo un cuestionamiento del modelo biomédico 6. Los factores ambientales se suman a factores políticos, económicos y culturales de conformación de los territorios para explicar la enfermedad y las disparidades en salud. El territorio se lee en este caso como espacialización del poder del Estado, como una entidad político-administrativa y escenario físico, donde se sitúan los determinantes sociales de la enfermedad. En esta perspectiva, las unidades territoriales (localidades, barrios, comunas, municipios, regiones) son organizadas y administradas de acuerdo a la espacialización del poder estatal, cuyas acciones deben dirigirse a cerrar las brechas en salud; los factores económicos, políticos y culturales de esas unidades territoriales aparecen como partes separadas que contribuyen diferencialmente a explicar los desenlaces en salud.

La discusión de la propuesta de Determinantes Sociales de la Salud (DSS) ha sido relacionada con esta manera de entender el territorio 23 . El énfasis en las condiciones sociales de vida, en la cuales la gente vive y trabaja, permiten la jerarquización de los DSS para entender en diferentes niveles la situación de salud de las poblaciones. Se trata de una geografía de las patologías o nosografía, que identifica y analiza patrones de distribución espacial de las enfermedades, sus determinantes y las desigualdades territoriales en salud, junto con su correspondiente georreferenciación de componentes relacionados con infraestructuras y de recursos humanos del sistema de salud 4 , sin considerar las interacciones humanas y su carácter histórico, político y económico, que permite la configuración de territorialidades no delimitadas ni gestionadas exclusivamente por las acciones gubernamentales.

Los avances frente a esta forma de entender el territorio pueden ilustrarse a través de los trabajos de Diez Roux 8, quien ha propuesto replantear el énfasis en los factores de riesgo de nivel individual para hacer un análisis contextual y multinivel de la relación entre áreas socioeconómicas y desenlaces en salud. Para abordar las categorías mediadoras de esta relación, la autora diferencia el efecto de contexto -bajo el cual se entienden los resultados en salud, a partir de variables como el área o las propiedades de un grupo-, del efecto de composición -que responde a características de los individuos que viven en diferentes áreas-. Así, tanto las áreas geográficas específicas, como la gente que habita esas áreas, constituyen niveles diferentes de explicación de los desenlaces y las desigualdades en salud 7,11,12

La propuesta de los DSS constituye un avance significativo para considerar la relación territorio y salud bajo una mediación social, pero deja abierta al mismo tiempo la necesidad de considerar elementos macro políticos que articulan esas diferentes dimensiones de determinación social de manera compleja, especialmente cuando se considera que la distribución de desigualdades territoriales no es azarosa, ni el mero efecto de las características espacio-ambientales de los territorios (locales, regionales, nacionales). Tanto las personas, como los lugares donde acontece la vida, están afectados por escalas superiores de poder; de aquí la urgencia de una reflexión más amplia respecto a las políticas neoliberales como generadoras de injusticia, desigualdad social y daño ambiental 10; esto es, generadoras de unos modos de ordenamiento del territorio bajo los intereses globalizadores del mercado 1,9.

Es bajo la necesidad de esa reflexión política, donde tienen lugar la crítica y la construcción ampliada del vínculo territorio y la salud en salud pública, especialmente en la tradición latinoamericana de la medicina social y la salud colectiva 4 . Influenciados por la concepción materialista del territorio en la geografía social 1,9,27,28, en la perspectiva latinoamericana de determinación social de las desigualdades en salud, se concibe el territorio como un producto social, resultado de la dinámica de los modos de producción y reproducción social 29 ; en este sentido, está condicionado por lo natural, pero no reducido a sus condiciones geoecológicas 23,30. En este marco, el análisis de la salud no se limita a la distribución espacial de características físicas del ambiente que inciden en el perfil 
epidemiológico de una determinada población; tanto territorio como salud son al mismo tiempo procesos, y productos de relaciones sociales y modos de producción, que proponen formas específicas de relación con la naturaleza, de vivir y de enfermar.

En la perspectiva de la determinación social es competencia de la salud pública descentrarse de una relación instrumental de los sujetos con el ambiente, establecer una apuesta política por pensar el territorio como un proceso de configuración sociohistórico 19,31. Esto no significa ignorar la existencia de elementos bióticos del ambiente, pero sí acentuar la interacción entre procesos y dinámicas de diferentes escalas ambientales como configuradoras de perfiles de protección o deterioro de la salud 30. En este contexto, las desigualdades no serían pues el simple resultado de una lotería natural que sortea recursos según la pertenencia a territorios geográficos específicos; las políticas neoliberales, lejos de estimular la mejora de la calidad de vida poblacional, tienen efectos notables en un deterioro de la salud y un daño irreparable al medio ambiente, por lo que hay que reevaluar la idea de unas desigualdades naturalizadas en los territorios, para comprender a favor de qué poderes el territorio se ordena de manera desigual 10,27.

Las dificultades para lograr condiciones de justicia social se asientan entonces en los sistemas globales que regulan las prácticas entre los países y que reflejan el interés de los individuos y las corporaciones más ricas. Como lo propuso Santos 9 , la globalización del modelo neoliberal ha pretendido la instalación de un sistema mundo único y total, una mundialización de los individuos y lugares, dando como resultado un territorio producido desde arriba, ordenado en una geografía desigual, que no puede entenderse de forma azarosa o determinada por características ecológicas, pues responde a intencionalidades y racionalidades de nivel superior. Para el autor, el ordenamiento del territorio, con el fin de realizar la globalidad de la economía neoliberal, se refleja en formas concretas como la violencia, el despojo y el empobrecimiento económico, material, cultural y moral, que son posibles bajo el discurso de la competitividad. Desde este entendimiento, las desigualdades territoriales en salud son el producto de procesos supranacionales y nacionales de orden político y económico, que configuran territorios con condiciones materiales específicas para la existencia.

Este acercamiento a la salud y el territorio como productos sociales forma un movimiento fundamental, respecto a las concepciones centradas en el esencialismo de la salud y el ambiente en la salud pública, al situar el carácter social de la salud y de la relación de las personas con territorios socio-históricamente configurados; sin embargo, mantiene un fuerte énfasis en la discusión sobre estructuras sociales y elementos macropolíticos de esa relación. La propuesta es avanzar un paso más: “¿Cómo las personas, en comunidades concretas, viven esa relación con sus territorios locales como posibilitadora de la construcción de salud?”, “¿Cómo se articulan estas dinámicas globales y los condicionantes biofísicos y sociales en los microterritorios de la vida cotidiana de las personas?”.

\section{Territorialización, territorialidades y lugares: aportes de las ciencias sociales para un análisis socio-espacial de la salud}

Tanto la geografía humana como la sociología y la psicología social ambiental han propuesto concebir el ambiente, más allá que como contenedor indiferenciado de recursos bióticos, como espacio de vida: "El entorno no es simplemente una decoración. Empero, la mayoría de las investigaciones lo tratan como tal o lo consideran, en el mejor de los casos, como una variable perturbadora (parásito) de los fenómenos estudiados" 32 (p. 1). Este espacio vivido se sitúa histórica, política y económicamente a la vez que condiciona, como resultado de procesos de organización, significación y trasformación por parte de grupos sociales 33 . En este sentido, la geografía considera el mundo como un sistema complejo de interacciones entre el ambiente físico-biótico (condiciones geológicas y geomorfológicas, climáticas, biodiversidad, etc.), las relaciones sociales (leyes, de clase social, relaciones de poder, relaciones económicas) y el campo de la cultura material y simbólica 34 .

Para dar cuenta de ese sistema complejo de interacciones, que se sitúa en los territorios de vida de las personas, es preciso leer la configuración territorial en el marco de una dialéctica entre lo material y lo simbólico, que se define de maneras distintas según diferentes escalas.

El ámbito más general y amplio del ambiente puede ser entendido teóricamente desde la noción de espacio. Aunque la geografía clásica lo concebía desde una óptica ecológica-determinista, como "un 
receptáculo natural de la especie humana” 35 (p. 48), la geografía social ha puesto el énfasis en la noción de espacio como producto social; el espacio no sólo se demarca por la presencia física del individuo, sino por las interacciones sociales y las particularidades culturales de los grupos sociales. El espacio percibido (material), el espacio concebido (representado) y el espacio vivido (significado e imaginado) se articulan bajo relaciones de poder, dominación y resistencia 28. En este sentido, las nociones espaciales nos permiten entender cómo están distribuidos los procesos sociales a través del espacio-tiempo, pero bajo la perspectiva de que la estructura espacial es maleable, variable, relativa y relacional.

El énfasis en el espacio, como configurado socialmente por relaciones de poder, da lugar también a la noción de territorio. El territorio "significa algo más concreto, cercado y limitado (por límites administrativos, socioculturales, físicos, entre otros) (...) el espacio, al delimitarse, cercase o concretarse, se constituye en territorio" 35 (p. 49). El territorio se configura al mismo tiempo como materialidad, continente de producciones socioculturales y proceso de semantización. Ampliando la reducida significación del territorio como entidad político-administrativa, demarcada por fronteras "naturales", el territorio se hace referente de los procesos de identidad, de la representación del mundo social y de las prácticas sociales de las personas y grupos que lo transforman.

Para Porto-Gonçalvez 1, el territorio constituye una categoría densa que presupone un espacio geográfico apropiado, y esa apropiación -territorialización-crea las condiciones para la construcción de identidades -territorialidades-, las cuales están inscritas en procesos históricos, siendo por eso dinámicas y cambiantes, materializando en cada momento un determinado orden, una determinada configuración territorial, una topología social. "El territorio es por tanto material y simbólico al tiempo, biofísico y epistémico, pero más que todo es un proceso de apropiación sociocultural de la naturaleza y los ecosistemas que cada grupo social efectúa desde su cosmovisión u ontología 36 (p. 91). Se trata por tanto e un entramado de múltiples actores y materialidades humanas y no humanas: "Estamos lejos pues de un espacio-sustancia, y sí ante una triada relacional territorio-territorialidad-territorialización. La sociedad se territorializa siendo el territorio su condición de existencia material" 1 (p. 230).

Las principales funciones de la territorialidad en los seres humanos están referidas a los procesos de organización social y la construcción de la identidad; sin embargo, bajo el entendimiento del territorio como construcción social y espacio de poder, la actividad espacial de los actores es diferencial y por lo tanto su capacidad real y potencial de crear, recrear y apropiar territorio es desigual 37. Esta apropiación desigual puede entenderse por procesos políticos de orden más amplio (macrosocial), pero también por la posibilidad que tienen las personas y comunidades de configurar vínculos significativos para actuar sobre sus entornos próximos 38.

El concepto de lugar se ofrece como punto de articulación entre los vínculos identitarios y afectivos con el espacio vivido y las oportunidades de uso y transformación de los territorios, por parte de las comunidades que lo habitan. El lugar no se refiere sólo a la localización física de los perfiles de enfermedad y morbilidad (como en el caso de la epidemiología clásica), sino a un "redescubrimiento de lo local, al considerar lo cotidiano, el espacio vivido” 35 (p. 51). El lugar posibilita vislumbrar un territorio más cercano, lo familiar, las prácticas locales en tensión permanente con las globales. Es una porción del territorio que es objeto de significados y valores inseparables de la experiencia de quienes lo habitan, de sus pensamientos y sentimientos, de sus representaciones y prácticas sociales, que lo hacen cercano a la noción de identidad: "la experiencia humana es tributaria del lugar en donde ocurre" 32 (p. XIV).

Esta relación con los lugares no ocurre independientemente de los ordenamientos territoriales: los lugares con significado emergen en un contexto social y a través de relaciones sociales (escenario o dimensión local); se hallan ubicados geográficamente y a la vez relacionados con su trasfondo social, económico y cultural, proporcionando a los individuos un sentido de lugar y una identidad territorial subjetiva; adquieren significados profundos a través de acumulación constante de sentimientos y experiencias 39 . El lugar implica un espacio y un sujeto que posee la capacidad de apropiarse de él para habitarlo, para actuar sobre él.

Es entonces en los lugares o territorios micro, significados por las acciones individuales y colectivas, donde se construyen territorialidades alternativas, es allí donde los actores locales cuestionan los ordenamientos hegemónicos del territorio. Por eso, el territorio no puede ser pensado como mera base sobre la que la sociedad se erige, como si no tuviera mayores implicaciones para el devenir; sus límites no pueden seguirse pensando como definidos externamente para delimitar la soberanía de los estados, como si estos no tuvieran las marcas de los protagonistas internos que los instituyen 1. 
Esta comprensión de los lugares cotidianos de la vida como territorialidades específicas no admite la distinción entre el territorio y lo social, entre lo material y lo simbólico; toda apropiación material es al mismo tiempo simbólica, se trata de un híbrido: "El territorio es, ante todo, una dialéctica entre espacio $y$ sociedad. En el territorio, y a través de él, se articulan las relaciones de poder. Podemos entenderlo como la producción social del espacio, tanto como la manifestación espacial de la sociedad; en él se expresa la apropiación subjetiva-colectiva del espacio. Apropiar (se) el espacio, en un sentido amplio, involucra acciones materiales como ocuparlo o transformarlo, pero también incluye manifestaciones menos tangibles como proyectar identidad, dibujarlo, nombrarlo: representar el espacio es una forma de territorializarlo. Los mapas, los relatos sobre lugares que construimos y escuchamos, los nombres que los evocan, las imágenes fotográficas y audiovisuales, son todos medios a través de los cuales nos apropiamos del espacio. Desde esta perspectiva, en tanto espacio representado, en tanto construcción subjetiva, el territorio es una relación y esto implica, por ende, que está determinado históricamente, que está situado, que se expresa dentro de los límites de una cultura" 40 (p. 61).

El espacio es apropiado, grabado, marcado en un proceso histórico; y ese proceso de apropiación precisa entonces de una comprensión en diferentes escalas. Para Moser 41, el marco de desarrollo de la vida de las personas, donde éstas organizan su sociedad y construyen una identidad, incluye tanto aspectos físicos, como sociales, económicos y culturales, que son diferentes según los niveles geográficos, los tipos de relacionamiento con otros y el control percibido. Según el autor, es la interacción con el ambiente y con los otros la que posibilita apropiar la realidad y los procesos de simbolización que conducen el comportamiento humano. La oportunidad de apegarse a lugares específicos, de percibir influencia sobre esos lugares, de ubicarse en ellos y representarlos, de participar de la producción de signos culturales sobre ellos, permite la identificación de ciertos lugares como escenarios para vivir saludablemente; la apropiación individual o colectiva de un espacio se realiza sobre ese fondo de relaciones sociales, en un espacio común, que se constituye como lugar de referencia identitaria y lugar que ofrece seguridad y control.

Es así como la construcción de vidas saludables no puede ser pensada fuera de un territorio concreto que provea recursos materiales y simbólicos; tanto unas condiciones materiales dignas para la vida, como el apego, la identidad de lugar y el sentido de comunidad son necesarios para una vida saludable 41. El establecimiento de vínculos con los lugares privados -el hogar, el trabajo- y semiprivados -el barrio, la comunidad-, y de relaciones significativas en ellos, es tan definitorio de la salud, como la presencia de desigualdades territoriales y precarias condiciones de vida. Además, la vinculación con lugares donde se desarrolla la vida es central para comprender las acciones colectivas y el uso de los recursos políticos y ambientales para el mejoramiento de las condiciones de salud y la percepción de bienestar 32 .

El análisis de la categoría territorio como un espacio socialmente producido y un espacio apropiado, a través de las acciones conjuntas de las personas en los microterritorios, es urgente para una salud pública que debe enfrentarse a los problemas de salud que los flujos migratorios y los fenómenos de desterritorialización conllevan. Pensar el territorio, como mundo donde acontece la vida cotidiana, no significa desconocer los procesos biológicos y sociales de la configuración territorial, más bien implica comprender cómo estos se articulan para personas y comunidades concretas y bajo procesos de interacción y significación específicos de los microterritorios.

\section{Territorializar la salud: acción subjetiva y construcción de salud en los pequeños territorios}

La necesidad de integrar el análisis territorial en la comprensión de los procesos de salud conlleva, según lo proponen Íñiguez \& Barcellos 4, la búsqueda de racionalidades alternativas. El análisis de la salud no debe pensarse como intrínsecamente espacial, sino que debe orientarse a comprender la dialéctica entre materialidad y procesos de significación como posibilidad de construcción del bienestar de las personas y comunidades. Las diversas formas de despojo y vulneración de los derechos territoriales (como las que se presentan en desplazamientos ambientales, migraciones forzadas y desastres naturales, entre otras formas de conflictos socioambiental), han puesto de relieve los impactos sobre las condiciones de vida y de trabajo, el aumento de los procesos mórbidos, los daños a la identidad, la 
pérdida de seguridad vital y la desestructuración de redes sociales, efecto de la amenaza a las territorialidades habituales 27,36 .

Una comprensión ampliada de los procesos de territorialización, así como la identificación y localización de objetos en el espacio y de los usos de estos por la población, es importante para comprender las dinámicas sociales y la determinación de las vulnerabilidades de salud, originadas en las interacciones de grupos humanos en (y con) determinados espacios geográficos 20.

La pregunta por la configuración territorial en relación con la salud exige entonces los esfuerzos de los pensadores en salud pública, especialmente cuando se entiende que el proceso de apropiación del espacio para la vida -territorialización- es al mismo tiempo un proceso de construcción de salud. Ocupar, transitar, significar, disputar, transformar los territorios para construir colectivamente una vida saludable es central para la ordenación alternativa de los territorios y la resistencia ante las múltiples formas de vulneración de la salud en el mundo neoliberal.

Las desigualdades en salud están social y políticamente localizadas y varían en el tiempo; las relaciones socioespaciales injustas se materializan en diferentes escalas de la vida para dar lugar a procesos de fragmentación y segregación socioespacial, que dificultan la apropiación de recursos (económicos, sociales, espaciales, simbólicos) para la construcción de vidas saludables. Los procesos económicos, políticos y sociales situados en los microterritorios resultan así limitantes de la salud como "una forma de vivir autónoma y solidaria en el marco de las relaciones con la naturaleza, la sociedad y el Estado” 31 (p. 72).

Sin embargo, las desigualdades territoriales en salud deben entenderse también por la construcción social de la experiencia individual y colectiva. Categorías como apego al lugar, identidad de lugar, acciones colectivas y sentido de comunidad, son también centrales para situar la relación entre salud y territorio; pues si la salud no es el mero producto de las mentes individuales, sí es el resultado del capital social, de los procesos colectivos de apropiación y transformación de esas condiciones desiguales de existencia. Las condiciones de vida de los grupos sociales son definidas por un conjunto de necesidades, problemas e insatisfacciones que surgen en el proceso de materialización de la vida de los individuos y de las poblaciones, no son ajenas a la construcción del espacio geográfico, del lugar ni a su historia 5. El compromiso cívico, la confianza y la reciprocidad en las comunidades locales constituyen activos importantes en salud que dependen del vínculo con los territorios específicos y son claves para generar procesos de cambio frente a las injusticias en salud 38 .

La salud pública se ve enfrentada a un nuevo reto, el de grafiar los procesos de territorialización de la salud desde sus protagonistas. Para Porto 1,27, grafiar los territorios desde abajo es volver a las posibilidades de resistencia, de creación, de constitución de territorialidades alternativas a las que están dadas hegemónicamente por la ordenación del territorio hecha "desde arriba"; el territorio se configura por la acción de la gente, por la apropiación material y simbólica de sus mundos vitales. Asimismo, los procesos de construcción de salud no pueden simplemente ordenarse, imponerse por la política pública nacional o por estamentos internacionales que plantean directrices para el control de la salud al interior de los territorios-área administrados por los gobiernos. Los ordenamientos jurídicos del derecho a la salud han de sentar las bases mínimas de justicia social para el desarrollo de vidas saludables, pero el derecho a la salud sólo se realiza a través de las acciones de personas y comunidades concretas que potencian las condiciones territoriales para hacer frente al malestar y construir formas de vivir bien juntos; y puesto que la política pública en salud se inserta en la lógica más amplia de desarrollo económico neoliberal, se mantienen abiertas las tensiones entre lo que dictan los instrumentos jurídicos en salud pública y una salud pública que hacen y viven las personas en las micropolíticas de la vida cotidiana. Por esta razón una mirada escalar, que descomponga las conexiones entre las políticas globales y las formas locales de hacer salud es necesaria.

En lugar de mantener la perspectiva de una globalización hegemónica y homogénea que borra las relaciones diversas de las personas y comunidades con sus lugares de vida ${ }^{9}$, la salud pública debe atender a la persistencia de territorios diversos, donde se sitúan múltiples formas de construir y vivir la salud, donde las personas, en un auténtico ejercicio político, resisten a los ordenamientos socioespaciales dictados desde arriba para instituir nuevas configuraciones territoriales y novedosas formas de hacer salud. Estos dibujos alternativos del territorio y del proceso salud-enfermedad conllevan el reconocimiento de los pequeños territorios como espacios para la realización de los derechos: derecho a la identidad y a una particular forma de ver el mundo; derecho a un espacio para ser, para vivir 
de acuerdo a lo que se piensa y quiere como forma de vida; derecho al ejercicio del ser, a la autonomía, organización, participación; derecho a una visión propia de futuro y desarrollo ecológico, económico y social desde una cosmovisión propia; derecho al desarrollo propio de acuerdo a las aspiraciones y modos de concebir la vida, garantizando la permanencia y diversidad cultural 36 .

La reflexión respecto de esta transacción entre microterritorios y macroterritorios conlleva tres importantes consideraciones para la teorización del proceso de salud-enfermedad en la salud pública: la salud como algo más que el mal funcionamiento o respuestas de enfermedad ante agentes patógenos presentes en un espacio físico; la salud no reducida a la capacidad de adaptación o al "correcto" funcionamiento o equilibrio frente a las demandas sociales de orden mayor; y la salud como proceso de creación constante, de producción subjetiva, que se desarrolla en los lugares habitados. Ampliar la reflexión sobre el territorio en la salud pública es el paso siguiente para profundizar en la teorización del vínculo entre las personas y de las personas con sus territorios como soportes de vidas saludables: "separada la naturaleza del hombre y de la sociedad no es posible pensar en interacciones múltiples ni tampoco proponer equilibrios y límites" 31 (p. 67). Mirar la vida y la salud de las personas como procesos autopoiéticos, condicionados por estructuras biológicas y socioespaciales, pero abiertos a la producción constante de nuevas normas y autorregulaciones, es la forma de avanzar en la construcción de una salud pública alternativa. Esta mirada permite la apertura frente a las responsabilidades estatales en materia de justicia social y bienestar de los ciudadanos en los territorios. Más allá del Estado, salubristas y comunidades son también actores en la construcción de justicia social; de una justicia situada en las particularidades de las comunidades, que reconozca la diversidad de las territorialidades y las formas específicas hacer salud.

\section{Conclusiones}

La salud pública está en deuda con ampliar la concepción de la importancia del territorio en la salud de las personas, bajo el entendimiento de ambos, territorio y salud, como procesos dinámicos que se concretan en las agencias específicas de las personas sobre sus lugares de vida. Esta ampliación de la mirada precisa de: una lectura de la relación territorio y salud que integre materialidades concretas, apropiaciones, trasformaciones y simbolismos de lugares específicos; una concepción de la salud como dialéctica de ajuste y creación, resultado de las condiciones materiales de la vida, pero también de procesos de interacción y simbolización con los otros; una concepción de la salud pública como campo de conocimiento y acción interdisciplinar, que involucra la participación de actores concretos -no sólo los estatales- e integra saberes diversos, que propone una comprensión situada; y, en este sentido, una concepción de la subjetividad como proceso que ocurre en ambientes y bajo condiciones sociales específicas, y de un sujeto que es agente, que crea y recrea las condiciones de su vida con base en los límites impuestos por su existencia material, pero también de acuerdo sus necesidades, motivaciones, deseos y expectativas.

Asimismo, un análisis territorial de los procesos de salud permite entender que las desigualdades territoriales en salud no son azarosas ni determinadas por procesos naturales de las áreas-ambientes. Las desigualdades en salud pueden entenderse como producto de condiciones materiales de existencia, pero también por la construcción de experiencias individuales y colectivas de las personas en sus lugares de vida; por lo que la articulación de las dimensiones naturales, sociales y subjetivas del territorio debe reintroducirse para su comprensión.

Finalmente, la propuesta de redimensionar la relación entre territorio y salud para la salud pública no significa un reduccionismo geográfico. El análisis debe trascender -no eliminar- las categorías físico-biológicas e integrar otras dimensiones materiales y simbólicas que permitan entender la salud como un proceso situado en territorios concretos. La comprensión de la dialéctica materialidadsignificado que emerge en la relación de las personas con el ambiente, bajo nociones como las de territorio, territorialidad y lugar, permitirá ampliar también las vías de conceptualización de la salud como proceso y producto de la interacción entre personas y de estas con sus territorios de vida. Este puede representar un avance importante frente a los intereses actuales de la salud pública en los conflictos socio-ambientales y los diferentes fenómenos disruptivos del vínculo con el territorio que dañan profundamente la salud de las personas. 


\section{Agradecimientos}

A Yadira Borrero Ramírez, por su acompañamiento en la construcción de este texto.

\section{Referencias}

1. Porto-Gonçalves CW. Da geografia às geografias: um mundo em busca de novas territorialidades. In: Ceceña AE, Sader E, editores. La guerra infinita: hegemonía y terror mundial. Buenos Aires: Consejo Latinoamericano de Ciencias Sociales; 2002. p. 217-56.

2. Pickenhayn J, Curto S. La geografía de la salud en la Argentina. Revista Geográfica 2005; 138:89-108.

3. Guerrand RH, editor. Las letrinas: historia de la higiene urbana. Valencia: Edicions Alfons; 1991.

4. Íñiguez LR, Barcellos C. Geografía y salud en América Latina: evolución y tendencias. Rev Cuba Salud Pública 2003; 29:330-43.

5. Peña J, Perdomo L, Cuartas D. Geografía y salud, una visión de pasado y presente. Entorno Geográfico 2013; 9:146-57.

6. Curto SI. De la geografía médica a la geografía de la salud. Revista Geográfica 2008; (143):927.

7. Íñiguez L. Territorio y contextos en la salud de la población. Rev Cuba Salud Pública 2008; 34(1) http://scielo.sld.cu/scie lo.php? script $=$ sci_arttext $\&$ pid $=S 0864$ $34662008000100006 \& \operatorname{lng}=$ es\&nrm=iso\&tlng $=$ es.

8. Diez Roux AV. Investigating neighbourhood and area effects on health. Am J Public Health 2001; 91:1783-9.

9. Santos M. Los espacios de la globalización. Anales de Geografía de la Universidad Complutense 1993; 13:69. http://revistas.ucm. es/index.php/AGUC/article/view/AGU C9393110069A.

10. Navarro V. What we mean by social determinants of health. Int J Health Serv 2009; 39:42341.

11. Borrell C, Pasarín MI. Desigualdad en salud y territorio urbano. Gac Sanit 2004;18:1-4.

12. Smyth F. Medical geography: understanding health inequalities. Prog Hum Geogr 2008; 32:119-27.

13. Sassen S. A massive loss of habitat: new drivers for migration. Sociology of Development 2016 2:204-33.

14. Tabbaa D, Seimenis A. Population displacements as a risk factor for the emergence of epidemics. Vet Ital 2013; 49:19-23.

15. Kraeh A, Froese FJ, Kim SG. Does socio-cultural and psychological adjustment influence physical health? The case of North Korean refugees in South Korea. Int J Intercult Relations 2016; 51:54-60.

16. Ibáñez AM, Vélez CE. Civil conflict and forced migration: the micro determinants and welfare losses of displacement in Colombia. World Dev 2008; 36:659-76.

17. Getanda EM, Papadopoulos C, Evans H. The mental health, quality of life and life satisfaction of internally displaced persons living in Nakuru County, Kenya. BMC Public Health 2015; 15:755. 
18. Agnew J. Spatiality and territoriality in contemporary social science. In: Piazzini CE, Montoya V, editores. Geopolíticas: espacios de poder y poder de los espacios. Medellín: La Carreta Editores; 2006. p. 15-29.

19. Samaja J. Desafíos a la epidemiología (pasos para una epidemiología "Miltoniana"). Rev Bras Epidemiol 2003; 6:105-20.

20. Monken M, Peiter P, Barcellos C, Rojas LI, Navarro M, Gondim G, et al. O território na saúde: construindo referencias para análises em saúde e ambiente. In: Barcellos C, editor. Território, ambiente e saúde. Rio de Janeiro: Editora Fiocruz; 2008. p. 23-41.

21. Tamayo JH. Salud pública e historia de la salud pública. In: Casas A, Congote JC, editores. salud y salud pública aproximaciones históricas y epistemológicas. Medellín: Hombre Nuevo Editores/Universidad de Antioquia; 2013. p. 59-84.

22. Caponi S. Miasmas, microbios y conventillos. Asclepio 2002; 54:155-82.

23. Sánchez-Calderón FV, León RN. Región, espacio y territorio en Colombia. In: Jiménez Reys LC, editor. Región, espacio y territorio en Colombia. Bogotá: Universidad Nacional de Colombia; 2006. p. 203-44.

24. Rodríguez F, Vaca D, Manrique L. Revisión de los conceptos de territorio, población y salud en el contexto colombiano. Cienc Tecnol Salud Vis Ocul 2012; 10:79-92.

25. Almeida-Filho N, Castiel LD, Ayres JR. Riesgo: concepto básico de la epidemiología. Salud Colect 2009; 5:323-44

26. Organización Mundial de la Salud. Temas en salud. Salud ambiental. http://www.who.int/ topics/environmental_health/es/.

27. Porto-Gonçalves CW. De saberes y de territorios: diversidad y emancipación a partir de la experiencia latino-americana. Polis Revista Latinoamericana 2009; 8:121-36.

28. Lefevre H. La producción social del espacio. Madrid: Capitan Swing; 1974.

29. Delgado M. El espacio público como representación. Espacio urbano y espacio social en Henri Lefevre. http://www.oasrn.org/pdf upload/el_espacio_publico.pdf.

30. Breilh J. La epidemiología crítica: una nueva forma de mirar la salud en el espacio urbano. Salud Colect 2010; 6:83-101.
31. Granda E. El saber en salud pública en un ámbito de pérdida de antropocentrismo y ante una visión de equilibrio ecológico. Rev Fac Nac Salud Pública 2008; 26 (Edición Especial):65-90.

32. Moser G. Psicología ambiental: aspectos de las relaciones individuo medio ambiente. Bogotá: Ecoe Ediciones; 2014.

33. Lindon A. La concurrencia de lo espacial y lo social. In: De la Garza E, Leyva G, editores. Tratado de metodología de las ciencias sociales: perspectivas actuales. México DF: Fondo de Cultura Económica; 2012. p. 582-622.

34. Delgado Mahecha O. Debates sobre el espacio en la geografía contemporánea. Bogotá: Universidad Nacional de Colombia; 2003.

35. Gutiérrez A, Sánchez L. Planeación para el desarrollo del territorio: perspectiva contemporánea. Medellín: Editorial Universidad de Antioquia; 2009.

36. Escobar A. Sentipensar con la tierra. Nuevas lecturas sobre territorio, desarrollo y diferencia. Medellín: Ediciones Unaula; 2014.

37. Montañez Gómez G, Delgado Mahecha O. Espacio, territorio y región: conceptos básicos para un proyecto nacional. Cuadernos de Geografía 1998; VII:120-35.

38. Bolam B, Murphy S, Gleeson K. Place-identity and geographical inequalities in health: a qualitative study. Psychol Health 2006; 21:399420.

39. Manzo LC, Perkins D. Finding common ground: the importance of place attachment to community participation and planning. J Plan Lit 2006; 20:335-50.

40. Granero G. Territorios de la desigualdad: política urbana y justicia espacial. Buenos Aires: Guadalupe Granero Realini; 2017.

41. Moser G. La psicología ambiental en el siglo 21: el desafío del desarrollo sustentable. Revista de Psicología de la Universidad de Chile 2003; 12:11-7. 


\section{Abstract}

The aim of this study is to extend the reading of the health-disease process from the territorial perspective. Theoretical production on the link between health and the environment should go beyond medical typologies and their emphasis on the distribution of environmental risks (physical, biological, and chemical) to acknowledge the social and subjective production of territories. In order to make progress with this theoretical production, public health should draw on the integration of concepts from the social sciences such as the appropriation of space, territory-territorialities, and places. In terms of scale, it should also focus on micro-territories, since the scenario of local territories and places of daily living are where lifestyles, illness, and the construction of health materialize.

Geography; Health-Disease Process; Environment and Public Health; Health Inequalities

\section{Resumo}

O objetivo deste trabalho foi avançar na leitura do processo de saúde-doença em termos territoriais. A teorização sobre o vínculo saúde e ambiente deve abranger desde as tipologias médicas, e sua ênfase na distribuição de riscos ambientais (físico, biológico, químico), em direção ao reconhecimento da produção social e subjetiva dos territórios. Para avançar em esta teorização a saúde pública deve enriquecer-se com a integração de noções próprias das ciências sociais, como a apropriação do espaço, território-territorialidades e espaços. Além disso, deve se acostumar desde um olhar hierárquico e se direcionar aos microterritórios, pois neste cenário dos territórios locais, e nos ambientes cotidianos da vida, e onde se concretizam os modos de viver, adoecer e de construir saúde.

Geografia; Processo Saúde-Doença; Meio Ambiente e Saúde Pública; Desigualdades em Saúde 